\title{
TINJAUAN \\ TAILING SEBAGAI SUMBER DAYA
}

Oleh :

\author{
Sabtanto Joko Suprapto \\ Kelompok Program Penelitian Konservasi Pusat Sumber Daya Geologi
}

\begin{abstract}
SARI
Tailing dari pengolahan bahan tambang, dapat mengandung bahan-bahan atau mineral-mineral yang berpotensi untuk diusahakan secara ekonomis. Selain mempunyai konotasi sebagai limbah, tailing masih mempunyai prospek untuk kembali diusahakan. Hal ini akibat komoditas tertentu yang terkandung saat proses pengolahan dilakukan belum mempunyai nilai ekonomi, atau harga komoditas tertentu mengalami peningkatan, sehingga yang masih terkandung dalam tailing menjadi bernilai ekonomi.

Nilai ekonomi tailing dipengaruhi juga oleh faktor-faktor sekala usaha, perkembangan teknologi, aturan perundangan dan faktor perizinan. Pengelolaan tailing untuk pengembangan usaha pertambangan dapat mempunyai kontribusi signifikan pada pengembangan ekonomi di daerah. Oleh karena itu inventarisasi, evaluasi dan pengembangan sumber daya tailing mempunyai arti penting yang sama dengan upaya pemanfatan cebakan-cebakan in-situ.
\end{abstract}

\section{ABSTRACT}

Tailing of mining processing, may contain materials or minerals which may be potential to be utilized economically. Despite having a connotation as waste, tailing may have a significant value of certain mineral resources. This is due to the fact that certain commodity contents have not economic values yet at the time of mine processing, but then this enable to become economical valued commodities as increasing price of them within tailing.

The economic value of tailing may be influenced by some factors such as scale of mine, technology development,regulation and permit. Tailing management for development of mining businessmay have significant contribution for regional economical development. Hence inventory, have the same important meaning as the endeavour in utilization of in-situ deposits.

\section{PENDAHULUAN}

Pembahasan tentang tailing umumnya dikaitkan dengan limbah beracun berbahaya yang berpotensi mencemari lingkungan. Hal tersebut tidak sepenuhnya benar, karena tailing sebagai ampas dari hasil pemurnian, pencucian atau pengolahan bahan galian dapat berpotensi mencemari apabila masih mengandung unsur toksik, akan tetapi apabila masih mengandung bahan galian yang ekonomis, berpotensi juga untuk dimanfaatkan.

Peningkatkan kualitas atau kemurnian bahan galian pada kegiatan usaha pertambangan umumnya dilakukukan melalui proses pengolahan. Proses ini dapat berupa pemisahan pengotor agar kualitas menjadi meningkat, pemurnian untuk mendapatkan kadar yang dikehendaki, atau pengolahan untuk mendapatkan semua komoditas ekonomi yang terkandung dalam bahan galian.

Proses pengolahan bahan galian untuk memisahkan komoditas ekonomi dari unsur atau bahan pengotor sangat sulit untuk mendapatkan perolehan (recovery) 100\%, yang berarti unsur atau bahan ekonomi tidak seluruhnya dapat terambil. Umumnya perolehan dari proses pengolahan yang berkisar $80 \%$ - $90 \%$ sudah dikategorikan optimal. Ini berarti bahwa 10 sampai $20 \%$ unsur atau bahan ekonomi akan terbuang atau masih terkandung di dalam tailing atau ampas pengolahan. Bahan atau unsur yang terbuang dapat dijumpai dalam presentase lebih dari $20 \%$ apabila kapasitas alat pengolahan memang kurang optimal. Bahkan pada sebagian metode pengolahan hanya mencapai perolehan $40 \% 60 \%$, sehingga hampir separuh bahan ekonomi masih terbuang bersama tailing.

Tailing dapat mengandung unsur atau bahan ekonomi dalam kadar yang masih tinggi, atau pada tambang yang mengolah bahan galian dengan cadangan besar, meskipun kadar bahan komoditas ekonomi pada tailing rendah, akan tetapi dengan kuantitas taling yang dihasilkan sangat besar maka secara kuantitas kandungan komoditas ekonomi yang masih terbawa bersama tailing sangat besar juga.

\section{TAILING BEBERAPA JENIS TAMBANG}

\section{Tailing Pencucian Batubara}

Pada penambangan batubara sering tidak dapat terhindarkan selain batubara ikut tergali juga bahan lain seperti lempung yang tercampur dengan batubara. Sehingga untuk menjaga kualitas batubara yang dihasilkan perlu 


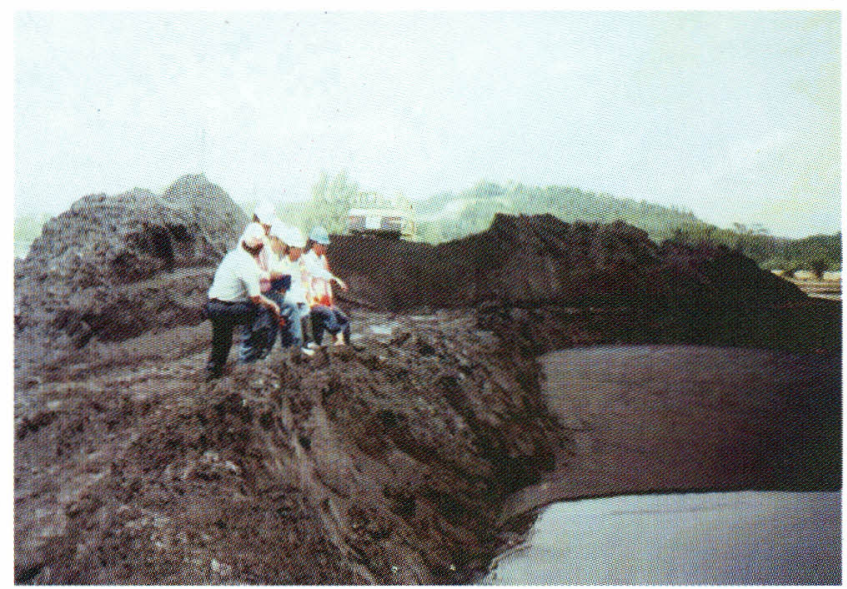

Gambar 1. Timbunan batubara halus ampas proses pencucian batubara (Tain dkk, 2001)

melalui proses pencucian. Pada proses pencucian batubara, fraksi halus dari batubara dapat terbawa bersama aliran air yang digunakan untuk mencuci. Sehingga proses pencucian dapat menghasilkan ampas berupa batubara halus yang secara kumulatif dapat dihasilkan dalam jumlah yang besar. Batubara halus ini masih dapat dimanfaatkan, di antaranya untuk bahan briket (Gambar 1).

\section{Tailing Tambang Kaolin}

Penambangan kaolin umumnya dilakukan dengan teknik penambangan terbuka dan cara semprot (hydraulicking). Penambangan kaolin di Belitung dilakukan dengan sistim gabungan antara tambang terbuka dan tambang semprot. Artinya endapan kaolin yang telah dikupas tanah penutupnya dengan ketebalan antara $2 \mathrm{~m} 7 \mathrm{~m}$, disemprot dengan menggunakan monitor tekanan tinggi. Kedalaman penambangan mencapai $15 \mathrm{~m}$ atau sangat tergantung pada kadar kaolin pada endapan yang ditambang.

Pada tambang kaolin, untuk mendapatkan kaolin dengan kualitas tinggi perlu dilakukan pencucian untuk menghilangkan bahan pengotor. Kaolin hasil proses pelapukan granit cenderung mengandung juga mineral resisten berupa silika.

Secara umum pengolahan kaolin dilakukan dengan penyemprotan endapan kaolin menggunakan monitor hingga terbongkar dan membentuk lumpur kaolin yang kental. Lumpur ini terbentuk dari campuran mineral kaolin, pasir kuarsa, dan air. Butiran kuarsa sangat membantu dalam pembentukan lumpur. Makin tinggi kandungan pasir kuarsa dalam endapan kaolin yang disemprot, pembentukan lumpur akan lebih cepat dan mudah karena kaolin yang lengket pada kuarsa akan lepas membentuk lumpur. Sedangkan kaolin dengan kadar kuarsa rendah dan kadar kaolin tinggi, maka proses pembentukan lumpur kaolin relatif lebih lambat karena kaolin akan liat, lengket dan membentuk bongkahan

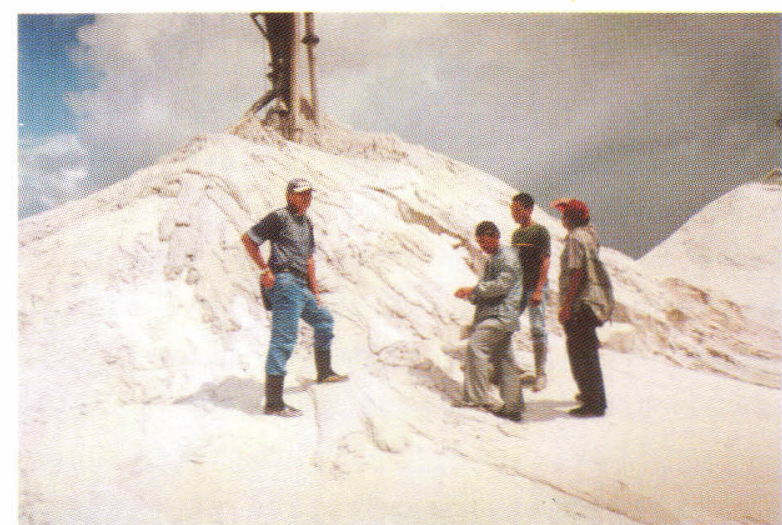

Gambar 2. Tailing berupa pasir kuarsa hasil penyaringan kaolin, Belitung, Babel (Ishlah dkk, 2002)

kaolin dalam lumpur dan ikut terpompa ke tempat penyaringan mekanik. Bongkahan kaolin ini mengganggu proses penyaringan, apabila bongkahan ini dominan pada saringan, alat ini harus dibongkar untuk dibersihkan. Untuk mencegah pengumpulan bongkahan kaolin, dilakukan dengan penyemprotan ulang sebelum dilakukan proses penyaringan serta pemilihan endapan kaolin yang mengandung silika tinggi.

Selanjutnya lumpur kaolin tersebut dialirkan melalui saluran-saluran dan ditampung pada cekungan yang lebih rendah di dalam kolong penambangan yang berfungsi sebagai bak penampung. Dari tempat penampungan, lumpur kaolin tersebut dipompakan ke tempat penyaringan mekanis untuk membuang kotoran organik/tumbuhan dan material kasar.

Proses selanjutnya, lumpur akan disaring melalui saringan dengan ukuran tertentu sebagaimana permintaan pembeli (umumnya 325 mesh) unituk memisahkan kaolin dan pasir kuarsa. Lumpur kaolin hasil penyaringan yang telah bersih dimasukkan ke dalam bak penampungan untuk dilanjutkan dengan proses pengendapan. Proses pengendapan ini dilakukan dengan mendiamkannya.

Endapan kaolin yang diendapkan dalam bak penampung, selanjutnya dikeringkan dengan menggunakan pemanas listrik/oven. Kaolin murni yang dihasilkan digiling menjadi tepung dengan ukuran 325 mesh (setara dengan 45 mikron).

Pasir kuarsa sebagai bagian dari penyusun endapan kaolin, menjadi hasil sampingan dari pengolahan kaolin yang untuk pemanfaatannya langsung pada tahapan pengangkutan. Sehingga nilai ekonomi pasir kuarsa akan meningkat, mengingat tanpa beaya pemisahan dari bahan pengotor.

\section{Tailing Tambang Tembaga}

Tambang tembaga di Mimika merupakan tambang terbesar di Indonesia dan termasuk ke dalam tiga besar di 
dunia. Cadangan emas sebagai mineral ikutan merupakan yang terbesar di dunia. Cebakan bijih utama berupa tipe porfiri $\mathrm{Cu}-\mathrm{Au}$ dan tipe skarn, mempunyai cadangan per 31 Desember 2005 sebesar 40,3 milyar pon logam tembaga, 43,9 juta ons logam emas dan 127 juta ons logam perak. Perolehan pada proses pengolahan dengan produk berupa konsentrat adalah sebesar $89 \%$ untuk $\mathrm{Cu}, 83 \%$ untuk Au. Kadar logam pada konsentrat adalah sebesar 30\% $\mathrm{Cu}$ dan $41 \mathrm{gr} /$ ton $\mathrm{Au}$ (PT. Freeport Indonesia).

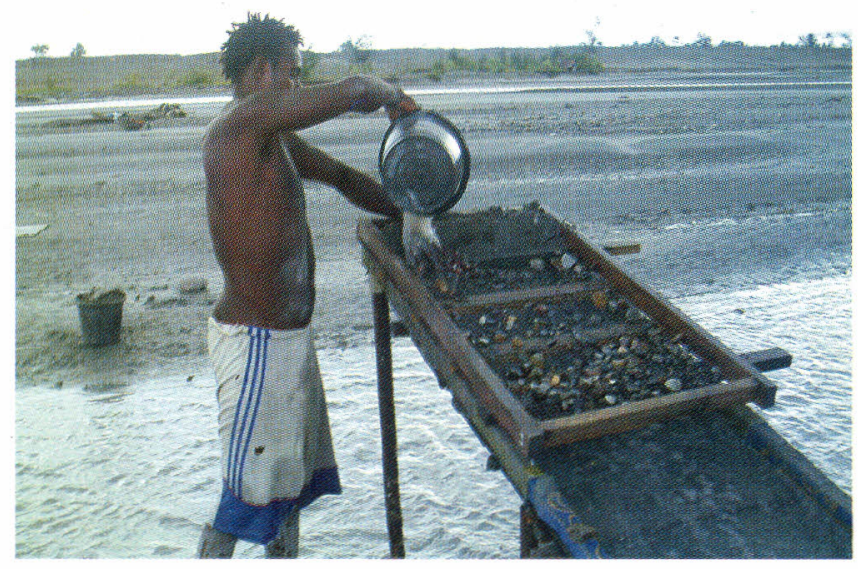

Gambar 3. Pengolahan emas dari tailing tambang tembaga, Mimika, Papua

Dengan recovery (perolehan) pengolahan sekitar $83 \%$, maka emas yang akan terbuang bersama tailing akan berjumlah sekitar 7,463 juta ons. Pada pengelolaan tailing tambang tembaga dengan mengalirkan tailing pada badan air, emas mempunyai berat jenis besar akan terpilah dari bahan ringan, sehingga akan ada pengkayaan kandungan emas, yaitu pengendapan emas akan terjadi pada daerah dengan arus sungai tinggi atau cenderung mengumpul pada bagian hulu (Gambar 3).

\section{Tailing Tambang Emas Hasil Amalgamasi}

Pengolahan bijih emas pada pertambangan rakyat dilakukan dengan dua cara, yaitu amalgamasi dan sianidasi. Metoda amalgamasi (Gambar 4) mengolah dengan bahan

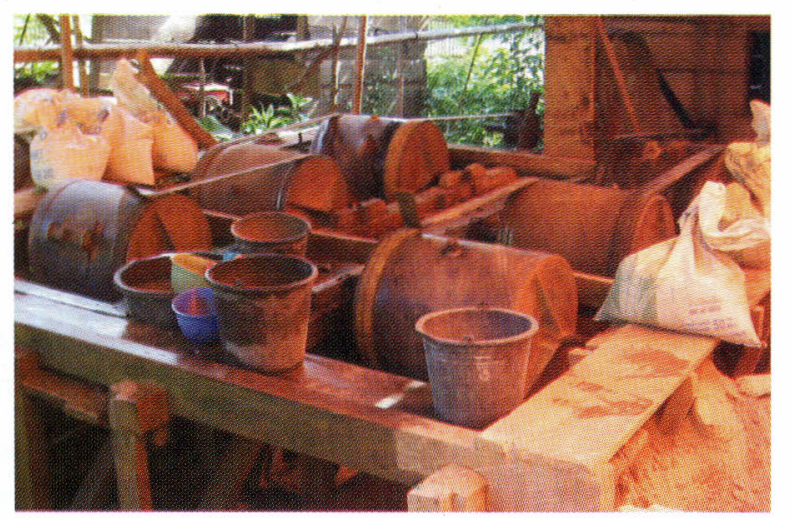

Gambar 4. Tromol untuk amalgamasi emas menggunakan tenaga air, Boalaang Mongondow, Sulut

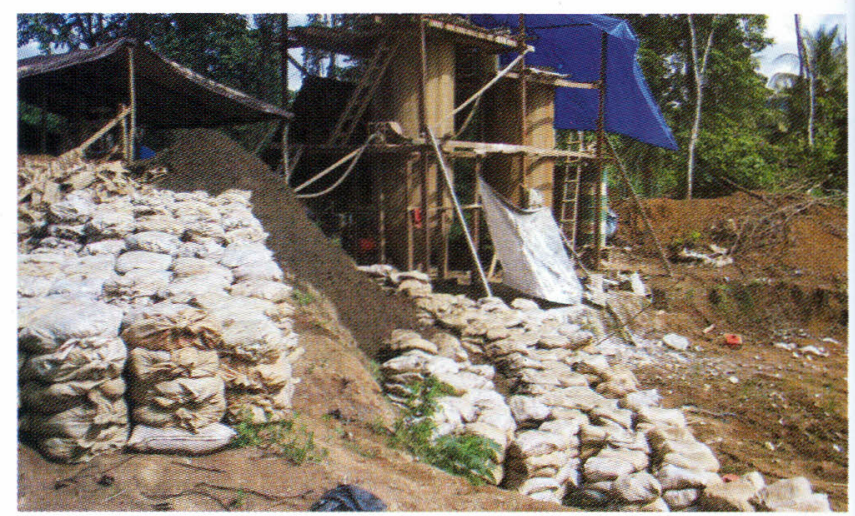

Gambar 5. Tailing hasil pengolahan bijih emas sistim amalgamasi, diolah kembali dengan sistim sianidasi, Halmahera Utara

baku berupa bijih emas yang sudah dihancurkan, sedangkan sianidasi mengolah tailing dari proses amalgamasi (Gambar $5)$.

Pada proses pengolahan menggunakan metoda amalgamasi, bijih berupa urat kuarsa ditumbuk sampai ukuran sekitar $1 \mathrm{~cm}$, selanjutnya dimasukkan ke dalam tromol. Pada tiap tromol diisi bijih sebanyak $1 / 3$ dari volume tromol, merkuri 0,5 1 ons dicampurkan atau jumlahnya tergantung pada kadar emas pada bijih. Penggilingan menggunakan tromol dilakukan rata-rata selama 8 - 12 jam atau tergantung pada kekerasan bijih, dengan putaran \pm 60 rpm. Untuk menggerakkan tromol menggunakan tenaga mesin atau aliran air sungai (Suprapto, 2006).

Pengolahan dengan metoda sianidasi menggunakan bahan baku tailing hasil proses amalgamasi mulai marak dilakukan pada tiga tahun terakhir, terutama di daerah Sulawesi Utara dan sekitarnya dengan meniru teknologi dari Filipina (Gambar 5 dan 6). Sebagai akibatnya tailing dari proses amalgamasi yang sebelumnya hanya dibuang, dapat dijual untuk diolah kembali dengan cara sianidasi.

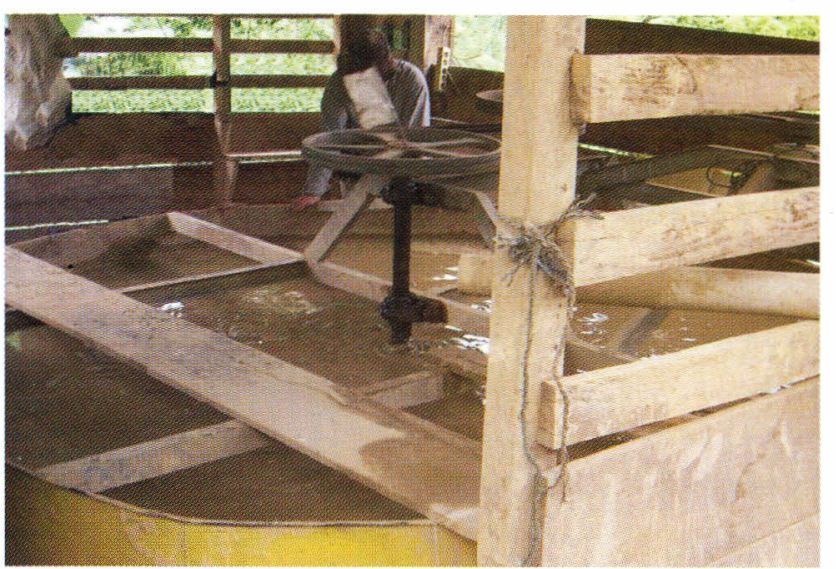

Gambar 6. Pengolahan emas dari tailing hasil proses amalgamasi dengan metoda sianidasi, Bolaang Mongondow, Sulut 


\section{Tailing Tambang Emas Aluvial}

Kegiatan penambangan dan pengolahan emas aluvial oleh masyarakat, umumnya tanpa upaya memanfaatkan mineral ikutan, sehingga terbuang bersama tailing. Proses pengolahan di beberapa lokasi tambang yang dilakukan oleh masyarakat, untuk meningkatkan perolehan emas, digunakan merkuri (proses amalgamasi) untuk menangkap emas terutama yang berbutir sangat halus.

Bahan galian yang terkandung pada cebakan emas aluvial, selain emas sebagai komoditas utama, terdapat mineral/ bahan ikutan yang kemungkinan berpotensi ekonomis. Mineral/ bahan ikutan tersebut sebagai matriks maupun fragmen dari endapan aluvial.

Sumber daya emas aluvial pada beberapa daerah prospek, umumnya telah dimanfaatkan, baik oleh pelaku usaha pertambangan maupun masyarakat. Kegiatan penambangan sebagian masih berlangsung sampai saat ini, sehingga sumber daya emas aluvial tersisa dalam kondisi insitu berjumlah relatif sedikit. Akan tetapi mengingat perkembangan kebutuhan komoditas tertentu seperti zirkon dan pasir besi yang terkandung juga sebagai mineral/ bahan ikutan pada cebakan emas aluvial, maka bahan galian pada beberapa wilayah bekas tambang emas aluvial, khususnya yang tersisa dalam bentuk tailing, dapat diolah kembali untuk memperoleh mineral/bahan ikutannya yang pada masa lalu belum mempunyai nilai ekonomi, Suprapto, 2007(Gambar 7)

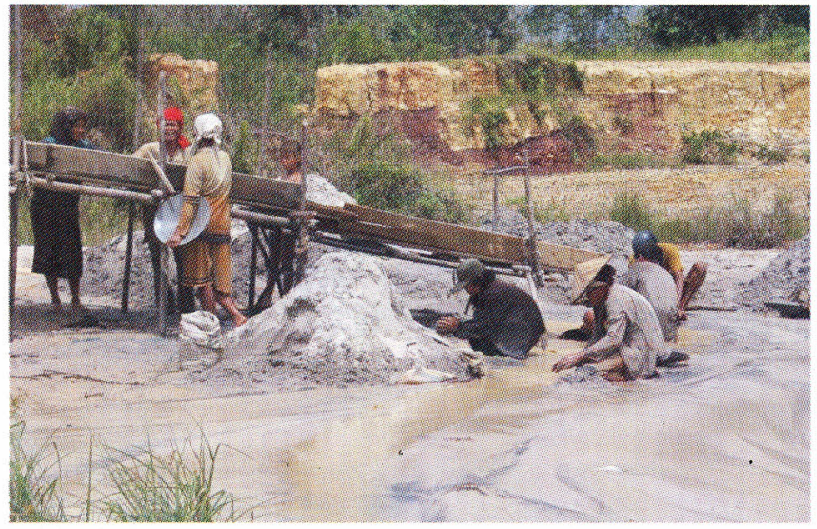

Gambar 7. Penambangan ilmenit dari tailing tambang emas aluvial, Monterado, Kalbar

Kandungan mineral ikutan berupa zirkon pada tailing tambang emas aluvial, di beberapa daerah prospek di Kalimantan telah diusahakan, di antaranya bekas tambang emas aluvial di S. Sekonyer (Rohmana dan Gunradi, 2006) dengan sebaran tailing seluas $3.777 \mathrm{Ha}$ dan volume sebesar 94.425.000 m3@894.gr/m3 zirkon. Dari pengolahan oleh tambang rakyat telah dihasilkan \pm 50.968 ton zirkon, sumber daya zirkon yang masih tersisa \pm 33.979 ton. Kandungan emas pada tailing@1,986 mg/m3, sumber daya emas pada tailing sebesar $\pm 187 \mathrm{~kg}$ berpotensi menjadi produk sampingan dari pengolahan zirkon.
Selain zirkon, tailing tambang emas aluvial dimanfaatkan juga kandungan ilmenitnya (Gambar 7). Pengolahan kembali tailing tambang emas aluvial untuk mendapatkan komoditas ikutannya, umumnya masih menghasilkan juga emas.

\section{Tailing Tambang Timah Putih}

Endapan timah putih tipe aluvial terbentuk dari hasil proses pelapukan mineralisasi tipe greisen, yang terbentuk pada batuan granit. Pelapukan bijih greisen yang diikuti erosi dan transportasi serta pengendapan kembali menjadi endapan aluvial, mempunyai kandungan material penyusun sesuai dengan batuan asalnya. Selain timah putih sebagai komoditas utama disertai mineral ikutan, juga dapat dijumpai endapan kaolin yang mengandung pasir kuarsa.

Penambangan pasir timah pada tailing tambang timah dijumpai di daerah Belitung dan Bangka. Umumnya penambangan berlangsung secara sederhana dengan menggunakan mesin semprot dan sluice box, yang dilakukan secara perorangan dan kelompok tambang (Gambar 8). Penambangan berlangsung di daerah tailing PT. Timah seperti yang ditemukan di sepanjang jalan antara Kelapa Kampit-Manggar-Silingsing-Gantung dan di sekitar tepi jalan raya Tanjungpandan-Badau (Widhiyatna dkk, 2006).

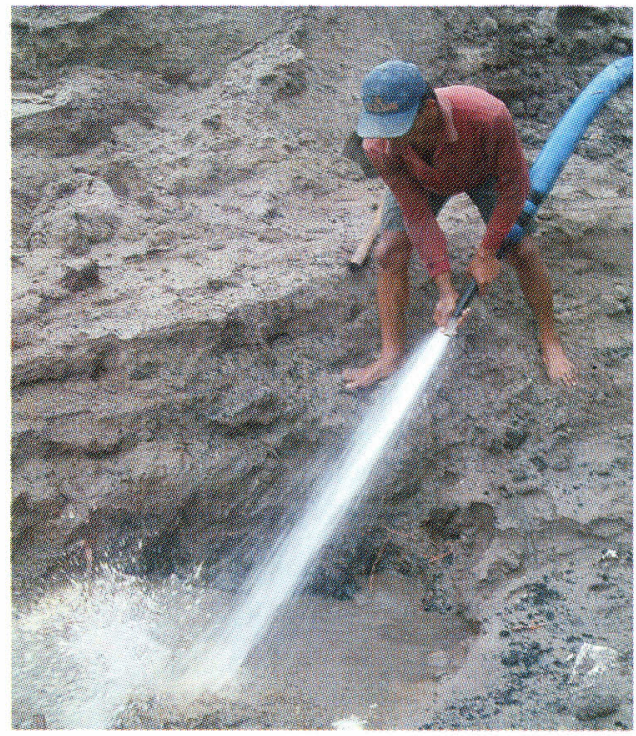

* Gambar 8. Penambangan timah putih dari tailing tambang timah putih, Belitung (Widhiyatna dkk, 2006)

Menurut informasi dari penambang, satu unit pengolahan untuk mendapatkan hasil ekonomis, minimal perminggu harus dihasilkan timah sebanyak $100 \mathrm{~kg}$, dengan harga jual yakni Rp. 20.000/kg. Kandungan timah pada tailing dapat mencapai 4550 gram timah perkubik. Kadar timah ini lebih tinggi dari CoG PT. Timah tahun 1994 yakni 300 gram timah per kubik. Kadar timah dalam tailing masih menguntungkan untuk diusahakan meskipun menggunakan peralatan sederhana oleh masyarakat. 
Penambangan pasir kuarsa dapat dilakukan juga dari endapan tailing tambang timah. Untuk memperoleh spesifikasi yang diperlukan pasir diolah atau dicuci untuk menghilangkan senyawa pengotornya, dan disaring menurut kebutuhan konsumen, seperti ukuran 80 mesh, 60 mesh, 40 mesh, 24 mesh, dan 20 mesh.

Penambangan pasir kuarsa dari endapan tailing tambang timah yang dilakukan di desa Silingsing Kecamatan Gantung, dilakukan oleh PT. Karya Mandiri. Pasir kuarsa dari tailing digali, diangkut ke tempat proses pengayakan. Ukuran ayakan yakni 24 mesh, 40 mesh, 60 mesh dan 80 mesh. Berdasarkan analisis mikroskopis contoh pasir kuarsa dari tailing timah yang ditambang oleh PT. Karya Mandiri, menunjukkan bahwa kadar kuarsa mencapai 99,98\%, ilmenit, piroksen, turmalin, zirkon dan rutil 0,001\%, garnet, anatas, leukosin dan kasiterit menunjukkan kadar sangat rendah (trace). Sedangkan analisis dari contoh hasil ayakannya menunjukkan kadar kuarsa 99,98\% - 99,99\%, zirkon $0,003 \%-0,007 \%$, rutil $0,002 \%-0,003 \%$ dan ilmenit mencapai 0,004\% (Widhiyatna dkk, 2006). Sehubungan dengan peningkatan kebutuhan dan harga zirkon akhir-akhir ini, penambangan tailing tambang timah untuk memanfaatkan kandungan zirkonnya juga mulai marak dilakukan (Gambar 9).

Pemanfaatan tailing tambang timah putih untuk pasir bangunan umumnya dilakukan di lokasi bekas tailing tambang timah yang telah ditinggalkan oleh PT. Timah Tbk. Penambangan pasir bangunan tidak memerlukan pengupasan atau pembersihan tanah penutup. Bahan baku pasir bangunan diambil dari bekas tailing timah yang ditambang di Tanjungpandan oleh PT. Bulu Tumbang, umumnya berkomposisi kuarsa dan sedikit felspar dan magnetit.

Dari hasil pengamatan mikroskopik, pasir bangunan tersebut tidak mengandung mineral berat ekonomis, kadar timah sangat rendah. Hasil analisis kimia conto pasir bangunan yang ditambang pada bekas tailing timah menunjukkan kadar 97,5\% $\mathrm{SiO} 2,0,9 \% \mathrm{Al} 2 \mathrm{O} 3$, dan $0,06 \% \mathrm{TiO} 2$. Sedangkan pasir hasil cucian menunjukkan kadar 98,2\% SiO2, 0,6\% Al2O3 dan 0,05\% TiO2.

Penambangan pasir bangunan hampir sama dengan penambangan pasir kuarsa. Perbedaannya, pada penambangan pasir bangunan tidak dilakukan penyaringan bertingkat, hanya dilakukan pencucian agar pasir bangunan tersebut bebas dari kandungan lumpur, material organik dan lempung. Produksi pasir bangunan yang dilakukan oleh PT Bulu Tumbang ditambang di pinggiran Tanjungpandan, diangkut ke pelabuhan menggunakan dump truck, dan dimuat ke ponton dengan kapasitas angkut 1300 ton (Widhiyatna dkk, 2006).

\section{Tailing Tambang Bauksit}

Bahan galian alumina (bauksit) selain sebagai bahan baku logam alumunium dapat pula digunakan sebagai bahan baku keramik berupa alumina (oksida aluminium). Untuk memperoleh kadar alumina yang tinggi bahan galian bauksit terlebih dahulu harus melalui proses pencucian, penggerusan dan kemudian proses pengkayaan alumina dengan menggunakan metoda bayer (Gambar 10).

Pada tailing pengolahan (pencucian) bijih bauksit terdapat kandungan pasir kuarsa yang tinggi, pasir tersebut dibersihkan dari pengotor dicampur semen dengan perbandingan $8: 1$ dapat dijadikan batako dan paving block. Hal tersebut telah diusahakan oleh mantan karyawan PT. Aneka Tambang di Bintan. Selain itu, dari hasil analisis kimia 9 conto tailing terdapat kandungan $\mathrm{Al} 2 \mathrm{O} 3$ antara 20,56\% 44,64\% (Rohmana dkk, 2007).

\section{PEMBAHASAN}

Bahan galian terbentuk di alam umumnya dengan kandungan penyusun yang terdiri dari lebih dari satu macam bahan yang potensial untuk menjadi bernilai ekonomi. Asosiasi kandungan bahan galian dapat berupa mineral/ bahan ikutan atau bahan galian lain yang secara stratigrafis dapat dibedakan dengan sebaran komoditas utamanya.

Mineral/ bahan ikutan pada deposit bahan galian apabila terbawa dalam proses pengolahan untuk mendapatkan komoditas utamanya akan ikut terpisahkan. Bahan ikutan yang terpisahkan dapat menjadi by product, atau kalau belum mempunyai nilai ekonomi akan terbawa dalam tailing. Perolehan pengolahan yang sangat sulit untuk mencapai $100 \%$, dengan pengertian bahwa tailing yang dihasilkan masih mengandung komoditas utama, maka dengan perkembangan teknologi atau perubahan nilai atau harga komoditas tertentu yang terkandung pada tailing, dapat menyebabkan tailing mempunyai nilai ekonomi untuk kembali diusahakan.

Kesalahan perizinan yang dikeluarkan kepada pelaku usaha pertambangan, sebagai misal dalam izin usaha pertambangan hanya menyebutkan komoditas kaolin yang diusahakan, sedangkan kaolin yang diusahakan cenderung mempunyai kandungan pasir kuarsa. Akibatnya pasir kuarsa yang secara otomatis ikut terpisahkan hanya diperlakukan sebagain tailing.

Pengolahan dengan menggunakan teknologi dengan perolehan rendah, tailing yang dihasilkan potensial masih mengandung bahan komoditas utama atau ikutannya dalam kadar yang relatif tinggi. Kondisi ini umum dijumpai pada tailing hasil kegiatan pertambangan rakyat.

Perolehan pengolahan lebih besar $80 \%$ umumnya dianggap sudah optimal. Wilayah usaha pertambangan dengan cadangan besar menghasilkan tailing dengan 


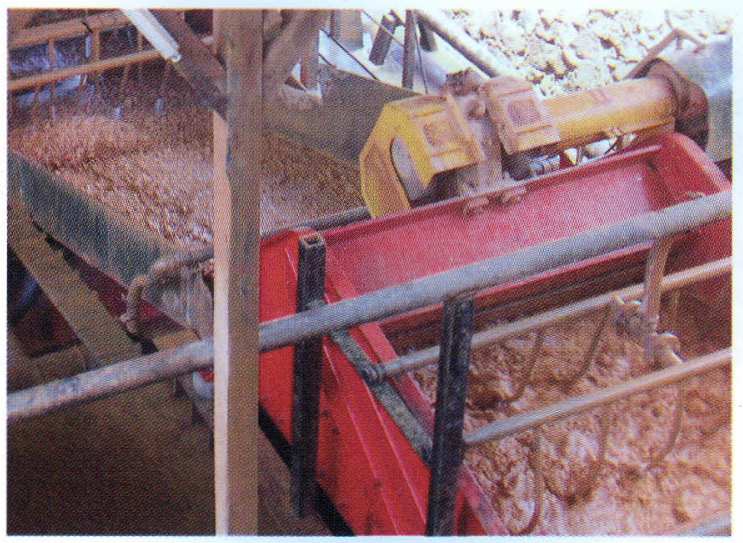

Gambar 10. Pencucian bijih bauksit (Rohmana dkk, 2007)

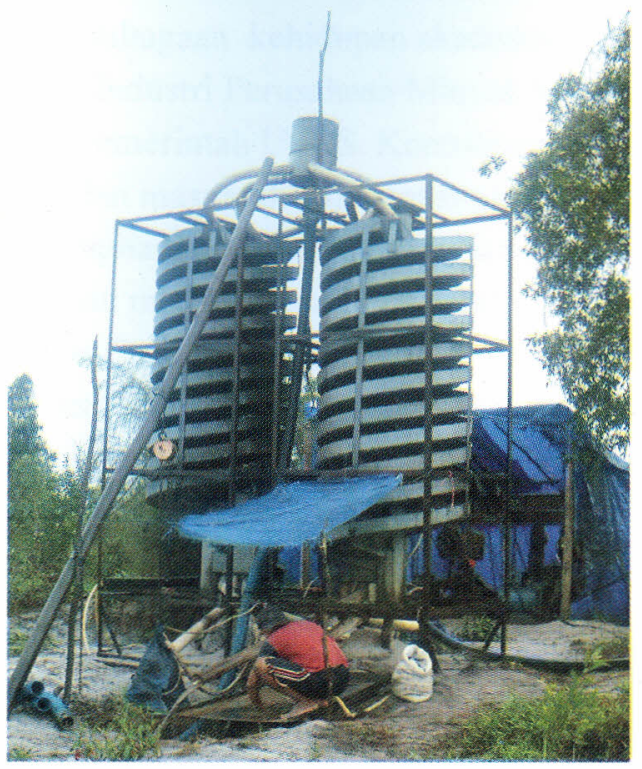

Gambar 9. Pengolahan zirkon dari tailing tambang timah putih, Belitung, Babel (Widhiyatna dkk, 2006)

kandungan komoditas utama pada tailing sekitar 20\%, maka nilai $20 \%$ dari cadangan asal yang sangat besar dapat berpotensi besar untuk diusahakan, khususnya untuk sekala usaha lebih kecil atau pertambangan rakyat.

Perubahan kebutuhan komoditas tertentu yang sebelumnya belum mempunyai nilai ekonomi, atau perubahan harga yang signifikan dari komoditas yang terkandung pada tailing, akan memberikan peluang mengusahakan kembali tailing.
Potensi ekonomia tailing tidak hanya yang berasal dari hasil kegiatan pertambangan rakyat yang umumnya mempunyai perolehan dari pengolahan rendah, akan tetapi dari kegiatan usaha pertambangan sekala besar yang meskipun perolehan pengolahan sudah optimal sesuai sekala usahanya, akan tetapi menghasilkan sumber daya tailing yang sangat besar yang dapat dimanfaatkan bahan ikutannya atau komoditas utamanya dalam sekala usaha yang lebih kecil.

\section{KESIMPULAN}

Tailing atau sering disebut ampas pengolahan dari kegiatan usaha pertambangan, dapat mempunyai nilai ekonomi untuk diusahakan, baik kandungan komoditas utama, bahan ikutannya, atau keseluruhan tailing itu sendiri untuk digunakan antara lain untuk bahan bangunan.

Nilai ekonomi tailing dapat langsung diusahakan saat dihasilkan, yaitu untuk kegiatan usaha pertambangan yang bersekala lebih kecil. Nilai ekonomi tailing dapat juga meningkat sebagai akibat harga dari komoditas yang terkandung meningkat, sehingga tailing hasil pengohalan dari tambang lama dapat kembali diusahakan.

Pengusahaan tailing dapat lebih mudah dibandingkan dengan mengusahakan cebakan insitu, hal ini kerena umumnya tailing sudah berada pada permukaan atau pada tempat dangkal, sehingga proses penggalian/ penambangan kembali memerlukan beaya lebih rendah.

Pengusahaan tailing untuk pengembangan usaha pertambangan dapat mempunyai kontribusi signifikan pada pengembangan ekonomi di daerah. Sehingga inventarisasi sumber daya tailing mempunyai arti penting yang sama dengan deposit yang masih in-situ.

\section{UCAPAN TERIMAKASIH}

Terimakasih disampaikan kepada rekan-rekan di Kelompok Program Penelitian Konservasi atas bantuannya, Sutrisno, M.Sc dan Dr. Bambang Tjahyono S, M.Sc atas saran dan koreksinya.

\section{ACUAN}

Ishlah, T., Pohan., M.P. dan Sukandar, M., 2002. Pengawasan Pemantauan dan Evaluasi Konservasi Sumber Daya Mineral, Direktorat Inventarisasi Sumber Daya Mineral, Bandung.

PT. Freeport Indonesia, 2006. Grasberg. Buku Pendamping Tur 2006. PT. Freeport Indonesia, Jakarta.

Rohmana, Djunaedi, E.K., dan Pohan, M.P., 2007, Inventarisasi Bahan Galian pada Wilayah Bekas Tambang di Daerah Pulau Bintan, Provinsi Kepulauan Riau, Pusat Sumber Daya Geologi, Bandung.

Rohmana dan Gunradi, R., 2006. Inventarisasi Bahan Galian Pada Wilayah PETI, Daerah Kotarawaringin Barat, Kalimantan Tengah, Pusat Sumber Daya Geologi, Bandung 
Suprapto, S.J., 2006. Sumber Daya Emas Primer Sekala Kecil Untuk Pengembangan Wilayah Pertambangan Rakyat Dengan Konsep Custom Mill. Buletin Sumber Daya Geologi, Vol-1. No-2.

Suprapto, S.J., 2007. Tinjauan Tentang Cebakan Emas Aluvial di Indonesia dan Potensi Pengembangan, Buletin Sumber Daya Geologi, Vol-2. No-2.

Tain, Z., Suhandi, Rosjid dan Rohmana, 2001. Pemantauan dan Pendataan Bahan Galian Tertinggal di Tambang Batubara di daerah Samarinda, Kaltim, Subdit Konservasi, Direktorat Inventarisasi Sumber Daya Mineral, Bandung

Widhiyatna, D., Pohan, M.P., Putra, C., 2006. Inventarisasi Bahan Galian Pada Wilayah Bekas Tambang, Pusat Sumber Daya Geologi, Bandung 